\title{
Kuluçkalık yumurtalarda bulunan bakteriyel izolatların morfolojik özelliklerinin belirlenmesi
}

\section{Determination of morphological characteristics of bacterial isolates in hatching eggs}

\author{
Sezai ALKAN ${ }^{1}$, Ömer ERTÜRK ${ }^{2}$, İsmail TÜRKER ${ }^{3}$ \\ ${ }^{1}$ Ordu Üniversitesi, Ziraat Fakültesi, Zootekni Bölümü, ORDU \\ ${ }^{2}$ Ordu Üniversitesi, Fen-Edebiyat Fakültesi, Moleküler Biyoloji ve Genetik Bölümü, ORDU \\ ${ }^{3}$ Bozok Üniversitesi, Ziraat Fakültesi, Zootekni Bölümü, YOZGAT \\ Sorumlu yazar (Corresponding author): S. Alkan, e-posta (e-mail): sezaialkan61@gmail.com \\ Yazar(lar) e-posta (Author e-mail): oseerturk@ hotmail.com, turker37@hotmail.com
}

\section{MAKALE BILGISII}

Alınış tarihi 10 Ocak 2018

Düzeltilme tarihi 20 Nisan 2018

Kabul tarihi 24 Nisan 2018

\section{Anahtar Kelimeler:}

Tavuk yumurtası

Kuluçkahane

Dezenfektan

Bakteriyel izolat

\section{ÖZ}

$\mathrm{Bu}$ araştırmada, kuluçkalık yumurtalarda bulunan bakteriyel izolatların morfolojik özelliklerinin belirlenmesi amaçlanmıștır. Bu amaçla damızlık bir işletmeden temin edilen 1920 adet kuluçkalık yumurtalardan rastgele 35 adet seçilmiştir. Yumurta örnekleri steril pamuk uçlu swaplarla yüzeylerinden taranarak bakteri yüklenmesi sağlanmıştır. Morfolojisine ve rengine göre birbirinden farklı olan koloniler belirlenmiștir. Bakteriyel izolatların biyokimyasal özelliklerinin belirlenmesinde Vitek 2 Advanced ColorimetryTM cihazı kullanılmıștır. Araștırmanın sonucunda 16 izolatın $15^{\prime} \mathrm{i}$ tanımlanmıs ve 13 farklı bakteri türü elde edilmiştir. Bakteriyel izolatlardan TB3-1'in \% 99 oranında Streptococcus pneumoniae, TB5-1, TB7-1 ve TB16-1'nın \%99 oranında Staphylococcus xylosus, TB6-1'nın \%99 oranında Micrococcus luteus ve TB8-1'inin ise \%95 oranında Staphylococcus pseudintermedius bakteri olduğu tespit edilmiştir. TB9-1'in \% 95 oranında Kocuria rosea TB10-1'in \%96 oranında Globicatella sulfidifaciens ve TB1-1'in \%98 oranında Staphylococcus simulans bakteri olduğu belirlenmiştir. TB12-1 ve TB13-1'in \%98 oranlarında Aerococcus viridans, TB14-1'in \%98 oranında Staphylococcus equorum, TB14-2'inin \%90 oranında Pantoea spp, TB2-1'in \%99 oranında Dermacoccus nishinomiyaensis ve TB0-1'in \%99 oranında Escherichia coli bakteri olduğu saptanmıştır. Araştırma neticesinde bakterilerin kaynağı farklı olsa da değişik yollarla yumurtalara bulaştığı görülmektedir. Bu nedenle yumurtaların kuluçkahaneye girmeden ve gelişim makinelerine yerleştirilmeden önce etkin bir şekilde dezenfekte edilmelerinin oldukça önemli olduğu sonucuna varılmıștır.

\section{ARTICLE INFO}

Received 10 January 2018

Received in revised form 20 April 2018 Accepted 24 April 2018

\section{Keywords:}

Hen egg

Hatchery

Disinfectant

Bacterial isolate

\begin{abstract}
In this study, it was aimed to determine the morphological characteristics of bacterial isolates in hatching eggs. For this purpose, 1920 hatching eggs were obtained from breeding commercial enterprise and 35 eggs were taken at random. Egg samples were scanned with sterile cotton-tipped swaps to provide bacterial load. Colonies which are different from each other according to morphology and coloring have been determined. Vitek ${ }^{\circledR} 2$ Advanced Colorimetry TM device was used to determine the biochemical properties of the bacterial isolates. As a result of research, 15 isolates of 16 isolates were identified and 13 different bacterial species were obtained. From the bacterial isolates, TB3-1 was found to be $99 \%$ of Streptococcus pneumoniae, TB5-1, TB7-1 ve TB16-1 was found to be 99\% of Staphylococcus xylosus, TB6-1 was found to be $\% 99$ of Micrococcus luteus, TB8-1 was found to be $95 \%$ of Staphylococcus pseudintermedius bacteria. Also, TB9-1 was found to be \%95 Kocuria rosea, TB10-1 was found to be $\% 96$ Globicatella sulfidifaciens, TB1-1 was found to be $\% 98$ Staphylococcus simulans bacteria. In same way, TB12-1 ve TB13-1 was found to be $\% 98$ Aerococcus viridans, TB14-1 was found to be \%98 Staphylococcus equorum, TB14-2 was found to be \%90 Pantoea spp, TB2-1 was found to be \%99 Dermacoccus nishinomiyaensis, TB0-1 was found to be \%99 Escherichia coli bacteria. As a result of the research, it was seen that the eggs were infected with bacteria in different ways, even though the source was different. Therefore, it was very important that the eggs were effectively disinfected before eggs enter the hatchery and eggs were placed in incubator.
\end{abstract}




\section{Giriş}

Kuluçka kanatlı üretim döngüsünün en önemli bölümlerindendir. Kuluçka esnasında meydana gelebilecek sorunlar üretimin henüz başında zaman ve para kaybına yol açabilmektedir. Kanatlı hayvan endüstrisinde kuluçkalık yumurtaların mikrobik kontaminasyonundan kaynaklanan kayıpların milyonlarca Avro'ya ulaştı̆̆ bildirilmektedir (Çadırcı 2009).

Mikroorganizmaların yumurta kabuğuna bulaşması, üreme organlarında olabileceği gibi ovopozisyon sonrasında da olabilir. Üreme organları ile olan bulaşma sıklıkla ovaryumdaki salmonella, mikoplazma ve bazı viral etkenler vasitası ile olur. Yumurta yumurtlamadan hemen sonra da mikroorganizmalar ile enfekte olabilir. En temiz yumurtanın kabuğunda dahi 300 ile 500 mikroorganizma vardır. Ortamın sıcaklık ve nemine göre mikroorganizmaların sayısı hızla artabilmekte ve 15 dakika gibi k1sa bir sürede 1500-3000'e, bir saat içerisinde ise 2000030000'e ulaşabilmektedir. $\mathrm{Bu}$ değerler kirli veya yer yumurtalarında çok daha yüksek olabilmektedir. Kuluçka işletmelerinin karlı olabilmesi için başarılı ve ekonomik bir dezenfeksiyon yöntemi uygulamaları gereklidir. Kuluçkalık yumurtalarda kullanılacak olan dezenfektan maddeler, mikroorganizmalar üzerine yüksek etkinlikte olmalı, insan ve hayvan sağlığına zarar vermemeli, suda çözünür olmalı, temini kolay ve ekonomik olmalıdır (Elibol 2014).

Hijyenik koşullara dikkat edilmeyen kuluçkahanelerde, özellikle E. coli, Staphylacoccus sp., Bacillus sp. ve Pseudomona sp. gibi bakterilerin yumurtalarda kontaminasyona neden olduğu bunun sonucunda da civcivlerde göbek iltihab1 (omphalitis) görüldüğü bildirilmiştir (Chute ve Gershman 1961; Ernst ve ark. 1980; Sheldon ve Ball 1986).

Kuluçkahanelerde dezenfeksiyon amaciyla en yaygın olarak kullanılan dezenfektan formaldehittir. Formaldehit, mükemmel bir antimikrobiyal ajan olmanın yanı sıra toksik bir kimyasaldır ve fumigasyon uygunsuz bir şekilde gerçekleştirilirse, embriyoya ciddi şekilde zarar verebilir. Formaldehit fumigasyonun amacı mikrobiyal yükü azaltmanın yanı sıra gelişen embriyoya olabildiğince az zarar vermektir. Yumurtalar Salmonella türlerine karşı oda sicaklığında $\left(25^{\circ} \mathrm{C}\right)$ ve ortam neminde en az 20 dakika süre ile $\mathrm{m}^{3}$ başına en az $600 \mathrm{mg}$ formaldehit gazı konsantrasyonu ile fumigasyona tabi tutulmalıdır. $\mathrm{Bu}$ koşullar altında yapılan fumigasyon, kabuk yüzeyindeki mikroorganizmaların \%99.8'ini öldürür ve embriyo ölümlerine etkisi yoktur. Zararlı etkilerinden korunmak amacıyla, formaldehit ile çalışılan ortamlarda formaldehit konsantrasyonunu izin verilen sınır olan $0.3 \mathrm{ppm}$ düzeyinin altında tutmak gerekmektedir (Ünsaldı ve Çiftçi 2010).

$\mathrm{Bu}$ araştırmada, bir damızlık işletmeden temin edilen kuluçkalık yumurtalardan rastgele seçilen yumurtalarda bulunan bakteriyel izolatların morfolojik özelliklerinin belirlenmesi amaçlanmıştır.

\section{Materyal ve Yöntem}

\subsection{Yumurta Yüzeyinde Bakteriyel Florayı Oluşturan Bakterilerin İzolasyonu ve Karakterizasyonu}

Yumurtalar kuluçka makinesine yerleştirilmeden önce rastgele 35 yumurta alınmış ve Mikrobiyoloji Laboratuvarına getirilmiştir. Yumurta örnekleri steril pamuk uçlu swaplarla yüzeylerinden taranarak bakteri yüklenmesi sağlanmış ve steril swapların Nutrient Broth (Merck) tüplere ekimi yapılmıştır.
Daha sonra ringer çözeltisi hazırlanarak her bir grup için ayrı ayrı 1/10 oranında seri sulandırma işlemi gerçekleştirilmiş olup sulandırma işlemi $\log 10$ 'a göre (10-1, 10-2 ve 10-3) yapılmıştır. $\mathrm{Bu}$ işlemlerin sonucunda 10-2 ve 10-3'lük sulandırmalardan alınan örnekler Nutrient Agar (Merck) üzerine $100 \mu \mathrm{L}$ ilave edilerek yayma plaka ekimi yapıldıktan sonra $28^{\circ} \mathrm{C}$ 'de 5-6 gün inkübasyona bırakılmıştır. İnkübasyon sonunda Nutrient Agar (Merck) üzerinde oluşan koloniler tek tek tespit edilmiştir. Koloni morfolojisine ve rengine göre birbirinden farklı olanlar belirlenmiş ve bu koloniler alınarak Çizgi Ekim Yöntemi ile Nutrient Agar (Merck) üzerine ekim yapılarak saf kültürler hazırlanmıştır. Birbirlerinden morfolojik olarak farklı olan örneklere çeşitli boyama yöntemleri uygulanmıştır. Eosin Methylene-blue, Lactose Sucrose (EMB) Agar ve MacConkey Agar'da ekim yapılmıştır. Boyama sonucunda bakteri şekli ve renklerine göre ayrilan örnekler deney materyali olarak kullanılmıştır. Saf kültürleri elde edilen izolatlara laboratuvar kodu verilmiştir (Benson 1985).

\subsection{Bakteriyel İzolatların Özelliklerinin VITEK ${ }^{\circledR} 2$ Advanced Colorimetry ${ }^{\mathrm{TM}}$ Sistemiyle Belirlenmesi}

İzolatların, Nutrient Agara (Merck) ekim yapılarak bir günlük inkübasyon sonrası, biyokimyasal özelliklerinin belirlenmesi amaciyla Ordu ve Giresun illerinin Gida Kontrol Laboratuvarlarında bulunan Vitek ${ }^{\circledR} 2$ Advanced Colorimetry ${ }^{\mathrm{TM}}$ cihazları kullanılmıştır. $\mathrm{Bu}$ işlem sırasında izolatların taze olmasına dikkat edilmiştir. İzolatlar için gram-negatif (GN), gram-pozitif (GP) ve Bacil (BCL) kartlar kullanılmıştır. İzolatlar $3 \mathrm{ml}$ salin çözeltisine (su içeriği $\% 0.45$ ile $\% 0.50$ $\mathrm{NaCl}, \mathrm{pH} 4.50$ ile 7) ve saydam plastik (polistiren) test tüpüne $(12 \mathrm{~mm} \times 75 \mathrm{~mm})$ gram pozitif ve gram negatifler için aseptik olarak aktarılmıştır. Organizmalar hazırlanan salin tüpüne steril öze ile inoküle edilmiştir. Kalibrasyonu yapılmış bir McFarland cihazı kullanılarak yoğunluğu McFarland No: 0.50-0.60'a eşdeğer olan homojen organizma süspansiyonu hazırlanmıştır. $\mathrm{Bu}$ işlem her bir örnek için tekrarlanmıştır. Bu işlemden sonra kaset VITEK ${ }^{\circledR} 2$ cihazına yerleştirilerek kartların dolum işlemi gerçekleşmiş ve 8 saat sonra sonuçlar alınmıştır (Verweij ve ark. 1999).

\section{Bulgular ve Tartışma}

VITEK ${ }^{\circledR} 2$ ile yapılan çalışmalar sonucunda 16 izolatın 15 'i tanımlanmış ve 13 farklı bakteri türü elde edilmiştir. Bu bakteriyel izolatların morfolojik özellikleri Çizelge 1'de verilmiştir. $\mathrm{Bu}$ izolatlardan TB3-1'in \%99 oranında Streptococcus pneumoniae (gram-pozitif bacterium), TB5-1, TB7-1 ve TB16-1'nın \%99 oranında Staphylococcus xylosus (gram-pozitif), TB6-1'nın \%99 oranında Micrococcus luteus (gram-pozitif) ve TB8-1'inin ise \% 95 oranında Staphylococcus pseudintermedius (gram-pozitif) bakteri olduğu tespit edilmiştir. TB9-1'in \% 95 oranında Kocuria rosea (gram pozitif coccus), TB10-1'in \% 96 oranında Globicatella sulfidifaciens (grampozitif) ve TB1-1'in \%98 oranında Staphylococcus simulans (gram pozitif coccus) bakteri olduğu belirlenmiştir. TB12-1 ve TB13-1'in \%98 oranlarında Aerococcus viridans (gram pozitif), TB14-1'in \%98 oranında Staphylococcus equorum (gram pozitif), TB14-2'inin \% 90 oranında Pantoea spp (gramnegatif), TB2-1'in \%99 oranında Dermacoccus nishinomiyaensis (Kytococcus sedentarius, gram pozitif) ve TB0-1'in \% 99 oranında Escherichia coli (gram-negatif) bakteri olduğu saptanmıştır. 
Çizelge 1. Bakteriyel izolatların morfolojik özellikleri.

Table 1. Morphological characteristics of bacterial isolates.

\begin{tabular}{|c|c|c|c|c|}
\hline Bakteri Adı & Gram, spor & Olasılık (\%) & Bakteri şekli, koloni şekli ve rengi & Lab Kodu \\
\hline Streptococcus pneumoniae & Pozitif & $\begin{array}{l}\% 99 \\
\% 99\end{array}$ & $\begin{array}{l}\text { Yuvarlak veya oval yapılı, } 2 \mu \mathrm{m} \text { ' den daha küçük, hareketsiz, } \\
\text { sporsuz, soluk sarı-krem renkli }\end{array}$ & $\begin{array}{l}\text { TB3-1 } \\
\text { TB5-1 }\end{array}$ \\
\hline & & $\% 99$ & 2-4 mm çapında yuvarlak, konveks ve parlak koloniler & TB7-1 \\
\hline Staphylococcus xylosus & Pozitif & $\% 90$ & oluştururlar, beyaz-parlak-beyaz renkli & TB16-1 \\
\hline Micrococcus luteus & Pozitif & $\% 99$ & $\begin{array}{l}\text { Yuvarlak veya oval yapılı, dörtlü şekilde, beyaz-parlak beyaz } \\
\text { renkli }\end{array}$ & TB6-1 \\
\hline Staphylococcus pseudintermedius & Pozitif & $\% 95$ & $\begin{array}{l}\text { 2-4 mm çapında yuvarlak, konveks ve parlak koloniler } \\
\text { oluşturur, beyaz-parlak beyaz renkli } \\
1,0-1,5 \mathrm{~mm} \text { boyutunda, hafif dış bükey, pürüzsüz ve pembe }\end{array}$ & TB8-1 \\
\hline Kocuria rosea & Pozitif & $\% 95$ & renkli & TB9-1 \\
\hline Globicatella sulfidifaciens & Pozitif & $\% 96$ & $\begin{array}{l}\text { kokus kısa zincir, beyaz veya krem renkli } \\
2-4 \text { mm çapında yuvarlak, konveks ve parlak koloniler }\end{array}$ & TB10-1 \\
\hline Staphylococcus simulans & Pozitif & $\% 98$ & oluşturur, beyaz-parlak beyaz renkli & TB1-1 \\
\hline & & $\% 86$ & Kok şeklindeki dörtlüler ve çiftler, koloniler küçük (1-2 mm), & TB12-1 \\
\hline Aerococcus viridans & Pozitif & $\% 98$ & sarımtırak renkli & TB13-1 \\
\hline Staphylococcus equorum & Pozitif & $\% 98$ & $\begin{array}{l}\text { Gram pozitif, küre şekilli, } 0.5-1.5 \mu \mathrm{m} \text { çapında, sporsuz, } \\
\text { genellikle kapsülsüz, beyaz ve limon sarısı renkli }\end{array}$ & TB14-1 \\
\hline Pantoea spp & Negatif & $\% 90$ & 2-3 mm çapında, dış bükey, çubuk şeklinde soluk sarı renkli & TB14-2 \\
\hline Tanımsiz & & & & TB15-1 \\
\hline $\begin{array}{l}\text { Dermacoccus nishinomiyaensis } \\
\text { (Kytococcus sedentarius) }\end{array}$ & Pozitif & $\% 99$ & $\begin{array}{l}\text { Kokus tetrad, düzensiz kümeler ve sekiz kübik paketler halinde, } \\
\text { kısa çubuklar, turuncu renkli }\end{array}$ & TB2-1 \\
\hline Escherichia coli & Negatif & $\% 99$ & Çomak şeklinde, sar1-kehribar renkli & ТВ0-1 \\
\hline
\end{tabular}

Streptococcus pneumoniae, toplumdan edinilmiş pnömoni, akut otitis media, sinüzit, kronik bronşitin akut alevlenmesi ve akut bakteriyel menenjitin en önemli etkenlerindendir (Kılıç ve ark. 2001). Bu bakteri kesimhane ve perakende satış için işlenmiş olan tüm et örneklerinde bulunmaktadır ( Turtura ve Lorenzelli 1994). Araştırmada bu bakteri tavuk yumurtasından izole edilmiştir. TB5-1 koduyla izole edilen Staphylococcus xylosus farklı araştırmacılar tarafindan da izole edilmiştir. Fermente sosislerden izole edilen Staphylococcus xylosus'un biyojen amin üretmediği belirlenmiştir.

İspanya'da üretilen sosislerinden izole edilen Staphylococcus xylosus suşlarının \% 76'sının biyojen amin olusturduğu belirtilmektedir (Suzzi ve Gardini 2003). Araştırma sonucunda kuluçkaya konulacak yumurtaların yüzeyinden Kocuria rosea ve Micrococcus luteus izole edilmiștir. Kaban ve Kaya (2007) tarafından yapılan araştırmada pastırmalarda katalaz pozitif kok olarak en fazla $S$. cohnii sub sp. cohnii bulunmuş olup bunu S. saprophyticus, Micrococcus luteus ve Kocuria rosea izlemiştir. Aynı çalışmada teknolojik öneme sahip olan S. xylosus sadece bir örnekte bulunmuştur. Vidal ve ark. (2000) yaptıkları bir araştırmada, bir toprak izolatı olan Kocuria rosea suşunun keratinolitik aktivitesini bildirmişlerdir. Micrococcus luteus, hem etlik kümes hayvanlarında hem de evleri çevreleyen yaşam alanlarında baskın suş olarak bulunmaktadır (Plewa ve Lonc-Copd 2011). Stafilokoklar insan ve hayvanlar için firsatçı patojenlerdir. Staphylococcus pseudintermedius (MRSP) köpeklerde deride, kulakta ve yaralarda enfeksiyona neden olan bir patojendir (Perreten ve ark. 2010). Staphylococcus pseudintermedius 'un neden olduğu köpek enfeksiyonları çoğunlukla deri enfeksiyonları, endometritis ve sistit enfeksiyonlarıdır (Cox ve ark. 1984). Razauskas ve ark. (2016) tarafindan yapılan bir araştırmada $S$. Pseudintermedius isimli bakteri farklı klinik enfeksiyonlara sahip olan köpeklerden izole edilmiş ve aynı zamanda patojenite faktörlerini kodlayan genlerde bu çalışmada belirlenmiştir. $\mathrm{Bu}$ arastırmada tavuk yumurtlarından izole edilen bakteriler arasında bu izolatın olması kümeslerin etrafinda köpek ve benzeri hayvanların muhtemel olduğunu ve bakterinin bir şekilde yumurtaya bulaştı̆̆ını göstermektedir. Globicatella sanguinis, seyrek olarak kan dolaşımı, merkezi sinir sistemi ve insanda idrar yolları enfeksiyonlarının olağandışı bir nedeni olarak rapor edilen ve nadir görülen patojenik bir gram pozitif kokustur. $\mathrm{Bu}$ cinsin diğer bir üyesi olan Globicatella sulfidifaciens bir insan patojeni değildir. $\mathrm{Bu}$ organizmanın tespiti, viridans grubu streptokoklara benzemekle birlikte, alışılmadık antimikrobik yatkınlık deseninden dolayı önemli olduğu bildirilmiştir (Miller ve ark. 2017). Yapılan bir diğer çalışmada yaklaşık olarak 10 Staphylococcus suşu izole edilmiş olup bu suşlar üç çeşit et ürününden değişken olarak izole edilmiştir. S. capitis, S. succinus ve $S$. equorum türleri sadece tavuk etlerinden izole edilirken, $S$. sciuri, $S$. aureus, $S$. simulans ve $S$. xylosus üç farklı etten izole edildiği bildirilmiştir (Attien ve ark. 2013). Bu çalışmada izole edilen bakterilerin çoğunluğunun hayvan kaynaklı izolatlar olduğu görülmektedir. $\mathrm{Bu}$ bakteri suşlarının tavuk kümeslerine veya yemlerine herhangi bir yolla bulaştığını söylemek doğru bir yaklamışdır. Yapılan bir araştırmada gram pozitif koklar perakende satış için kesilen ve işlenen kanatlı eti örneklerinde bulunmuştur. Bunlar Enterococcus faecalis (48 suş), E. faecium (16 suş), E. avium (7 suş), E. durans (4 suş), Aerococcus viridans (10 suş), Streptococcus morbillorum (2 suș), S. salivarius (1 suss), S. sanguis (1 suş), S. "milleri" (1 suş), $S$. pneumoniae (1 suş), $S$. acidominimus (1suş) ve Gemella haemolysans'tır (1 suş). Genellikle barsak yolunu kolonize eden bu türler hem insan hem de hayvan vücudunda bulunabilen bu türler potansiyel olarak patojenler olabilirler. Bunların varlıkları kesilen tavuklarda işlenen etin dışk1 kontaminasyonunun bir endikasyonudur (endojen kirlenme). Tespit edilen gram-pozitif koklar ve enterobakterlerin sayısının, enterokokların koliform bakterilerine oranla çok daha fazla olduğunu göstermiştir (Turtura ve Lorenzelli 1994).

Kümes hayvanlarının ve keçilerin deri ve yanaklarından izole edilen suşlar Staphylococcus arlettae'ye aittir. Staphylococcus equorum sağliklı atların derisinden izole edilen suşları içerirken, S. kloosii çeşitli yabani hayvanların ve çiftlik hayvanların derisinde bulunur. $\mathrm{Bu}$ yeni türlerin hücre 
duvarlarının kimyasal bileşimi, Staphylococcus xylosus ve Staphylococcus saprophyticus'un kimyasal bileşimlerine benzer olduğunu bildirilmiştir (Schleifer ve ark. 1984). Yapılan bir araştırmanın sonuçları TB2-1 nolu izolatın Dermacoccus nishinomiyaensis bakterisinin toprak örneklerinde mevcut olduğunu göstermiştir. $\mathrm{Bu}$ çalışmada ayrıca mikropların özellikle Kocuria kristinae'nin ve Dermacoccus nishinomiyaensis'in çözeltiye daldırılmış LDPE filmleri bozabildiği tespit edilmiştir. $\mathrm{Bu}$ bakterilerin plastikleri metabolizma için karbon kaynağı olarak kullanabildikleri belirlenmiştir (De Campos ve ark. 2011). Escherichia coli hem insanlarda hem de hayvanlarda enfeksiyonlara sebep olan ve normal florda bulunan bir bakteridir. Escherichia coli'nin(VTEC) verositotoksin (VT) üreten suşları ilk olarak 1980'lerin başında insan hastalığına bağlanmıştır (Riley ve ark. 1983). O zamandan beri artan frekansla VTEC ile enfeksiyon bildirilmiştir. VTEC, hafif hematolojik ülser, hemorajik kolit ve hemolitik üremik sendromun ishale bağl1 formunu içeren bir dizi rahatsızlığa neden olabildiği ve bakterinin meydana getirdiği bazı enfeksiyonların asemptomatik olduğu bildirilmiştir (Tarr 1995).

\section{Sonuç}

Tavukçuluk sektöründe damılılıçı ve kuluçkacı işletmeler sağlıklı civciv üretiminde birbirine bağımlı olarak faaliyet göstermektedir. Sağlıklı civciv ve sağlıklı sofralık yumurta üretebilmek için bu işletmelerin hijyenik koşullara ciddi bir şekilde uymaları gerekmektedir. Herhangi bir yolla mikroorganizma bulaşmasının olabileceği dikkate alınarak ve damızlık işletmeden başlayarak mikroorganizmaları oluşturan kaynakların ve bulaşma yollarının iyi bir şekilde belirlenip önleyici tedbirlerin alınması şarttır. Bu tedbirlerle birlikte işletmelerin planlı bir şekilde dezenfekte edilerek mikroorganizmaların üremesine firsat verilmemeli ve biyogüvenlik yönetmeliğinde belirtilen kurallara da uyulması gerekmektedir.

\section{Kaynaklar}

Attien P, Sina, H, Moussaoui W, Dadié T, Chabi Sika K, Djéni T, Bankole HS, Kotchoni SO, Edoh V, Prévost G, Djè M, BabaMoussa L (2013) Prevalence and antibiotic resistance of Staphylococcus strains isolated from meat products sold in Abidjan streets (Ivory Coast). African Journal Microbiology Research, 7(26): 3285-3293.

Benson HJ (1985) Microbiological Applications: A Laboratory Manual in General Microbiology, $4^{\text {th }}$ ed. W. C. Brown Publishers, Dubuque, Iowa.

Çadırcı S (2009) Disinfection of hatching eggs by formaldehyde fumigation - a review. Archive Geflügelkunde, 73 (2): 116-123.

Chute HL, Gershman M (1961) A new approach to hatchery sanitation. Poultry Science, 40: 468-571.

Cox HU, Newman, SS, Roy AF, Hoskins JD (1984) Species of Staphylococcus isolated from animal infections. Cornell Veterinary, 74: 124-135.

De Campos, A, Marconato JC, Martinsfranchetti SM (2011) Biodegradation of blend films PVA/PVC, PVA/PCL in soil and soil with landfill leachate. Brazilian Archives of Biology and Technology, 54(6): 1367-1378.

Elibol O (2014) Embriyo gelişimi ve kuluçka: Tavukçuluk Bilimi Yetiştirme, Besleme ve Hastalıklar, Editörler: Türkoğlu, M., Sarıca, M., Genişletilmiş 4. Baskı, Bey Ofset Matbaacılık, Ankara, s. 165206.
Ernst RA, Bickford AA, Glick-Smith J (1980) Microbiological monitoring of hatcheries and hatching eggs. Poultry Science, 59: 1604.

Kaban G, Kaya M (2007) Staphylococcus xylosus ve Lactobacillus plantarum Suşlarının Sucuğun Duyusal Özellikleri ve Renk Değerleri Üzerine Etkileri. Ankara Üniversitesi Ziraat Fakültesi Dergisi, 38(1): 83-89.

Kılıç A, Başustaoğlu A, Özyurt M, Güney Ç, Aydoğan H (2001) Klinik örneklerden izole edilen Streptococcus pneumoniae suşlarının penisilin direnci ve diğer antibiyotiklere duyarlılıkları. İnfeksiyon Dergisi, 15(2): 243-247.

Miller AO, Buckwalter SP, Henry MW, Wu F, Maloney KF, Abraham BK, Hartman BJ, Brause BD, Whittier S, Walsh TJ, Schuetz AN (2017) Globicatella sanguinis Osteomyelitis and Bacteremia: Review of an Emerging Human Pathogen with an Expanding Spectrum of Disease. Open Forum Infections Disease, 4(1): 277.

Perreten V, Kadlec K, Schwarz S, Grönlund Andersson U, Finn M, Greko C (2010) Clonal spread of methicillin-resistant Staphylococcus pseudintermedius in Europe and North America: an international multicentre study. Journal Antimicrob Chemother, 65(6): 1145-1154.

Plewa K, Lonc-Copd E (2011) Analysis of airborne contamination with bacteria and moulds in poultry farming: a case study, Polish Journal of Environmental Study, 20(3): 725-731.

Razauskas M, Couto N, Pavilonis, A, Klimiene I, Siugzdiniene R, Virgailis M, Vaskeviciute L, Anskiene L, Pomba C (2016) Characterization of Staphylococcus pseudintermedius isolated from diseased dogs in Lithuania. Polish Journal of Veterinary Science, 19(1): 7-14.

Riley W, Remis RS, Helgerson SD, McGee HB, Wells JG, Davis BR, Hebert RJ, Olcott ES, Johnson LM, Hargrett NT, Blake PA, Cohen ML (1983) Hemorrhagic colitis associated with a rare Escherichia coli serotype. New England Journal Medicine, 308: 681-685.

Sheldon B. W, Ball J (1986) Efficacy of ozon disinfection in poultry hatcheries. Industry Summary report 119, Southheastern poultry and egg association, Decatum. G.A.

Schleifer KH, Kilpper-Bälz R, Devries LA (1984) Staphylococcus arlettae sp. nov., S. equorum sp. nov. and S. k1oosii sp. nov.: Three New Coagulase-Negative, Novobiocin-Resistant Species from Animals. Systematic and Applied Microbiology, 5(4): 501-509.

Suzzi G, Gardini F (2003) Biogenic Amines in Dry Fermented Sausages: A Review. International Journal of Food Microbiology, 88(1): 41-54.

Tarr PI (1995) Escherichia coli O157:H7: clinical, diagnostic, and epidemiological aspects of human infection. Clinical Infections Disease, 20: 1-10.

Turtura GC, Lorenzelli P (1994) Gram-positive cocci isolated from slaughtered poultry. Microbiological Research, 149(2): 203-213.

Ünsaldı E, Çiftçi MK (2010) Formaldehit, kullanım alanları, risk grubu, zararlı etkileri ve koruyucu önlemler. YYÜ Veteriner Fakültesi Dergisi, 21(1): 71-75.

Verweij PE, Breuker IM, Rijs AJ (1999) Comparative study of seven commercial yeast identification systems. Journal of Clinical Pathology, 52: 271- 273.

Vidal L, Christen P, Coello MN (2000) Feather degradation by Kocuria rosea in submerged culture. World Journal Microbiology Biotechnology, 16: 551-554. 